\title{
Geospatial differences among natural regions in the utilization of maternal health care services in India
}

\author{
Anil Jagan Hiwale ${ }^{a, *}$, Kailash Chandra Das ${ }^{b}$ \\ ${ }^{a}$ Department of Geography, Bhusawal Arts, Science and P.O. Nahata Commerce College, Bhusawal, Maharashtra, 425201, India \\ ${ }^{\mathrm{b}}$ Department of Migration and Urbanization, International Institute for Population Sciences, Mumbai, Maharashtra, 400088, India
}

\section{A R T I C L E I N F O}

\section{Keywords:}

Natural regions

Caste

Utilization of maternal health

\begin{abstract}
A B S T R A C T
Background: The chances of a woman dying or becoming disabled during childbirth are closely connected to her socioeconomic status, cultural norms and values, and her home's geographical remoteness. Most of the studies were undertaken to address the issue of accessibility of the hospital's location and its impact on utilization of maternal healthcare utilization. Some studies also attempted to understand the pattern of utilization of healthcare utilization according to administrative and political regions.

Objectives: This study aims to identify the Geographical differences in the utilization of maternal health services in India according to geographical regions, caste, religion, wealth status, and place of residence.

Data and methods: Data for analysis was taken from the National Family Health Survey-4 (2015-16). Data management and analysis were performed using statistical software Stata 13.0. To identify the regional differences in the use of maternal healthcare services, study used the 75 th round of NSS's classification of India into 88 natural regions. Regional variations in the usage of maternal health care were plotted using ArcGIS 10.5, and the bivariate method.

Results: Results shows that the utilization of partial ANC ranges from 33.8\% to $91.9 \%$. Utilization is lowest in the Northern Kerala region (33.8\%) and, in ascending order, higher in Lakshadweep (34.4\%), Goa (36.2\%), Puducherry (43.1\%), Southern Kerala (43.4\%), Inland Tamil Nadu (44.5\%), and Andaman and Nicobar Island (46.2\%), the mountainous region of Jammu and Kashmir (46.7\%), Coastal northern Tamil Nadu (49.9\%) and Eastern Maharashtra (51.6\%). Institutional delivery was the highest in Northern Kerala (100\%) and lowest in the Nagaland (35.7\%). Near-universal institutional delivery was also found in Southern Kerala (99.9\%), Puducherry (99.9\%), Coastal Northern Tamil Nadu (99.6\%) and Lakshadweep (99.2\%).

Conclusions: Differences in the utilization of MCHS by women can be seen among India's natural regions. Utilization is lagging in the Himalayan Mountain ranges, areas with dense forest cover, the Ganga and Brahmaputra plains, and the Desert region of Rajasthan.
\end{abstract}

\section{Introduction}

In 2000, the United Nations Millennium Summit adopted what is now known as the Millennium Declaration. The Declaration identified targeted outcomes in eight human development indicators, officially designated as the Millennium Development Goals (MDGs). These targets were to be achieved by 2015. MDG 5 (the Fifth Millennium Development Goal) was related to maternal health and had two components-MDG5A and MDG-5B. MDG-5A stipulated a reduction of the maternal mortality rate by $75 \%$ (based on 1990 figures) by 2015 . This was expected to be achieved by increasing the proportion of births attended by skilled health personnel. MDG-5B was targeted at universal access to reproductive health. However, as a country, India failed to achieve the targets set in MDG-5. Only a few states-Kerala, Maharashtra, Tamil Nadu and Andhra Pradesh, to name some-achieved them. ${ }^{1}$ Subsequently, the Sustainable Developmental Goals which are expected to be met by $2030 .^{2}$

Due to the efforts of United Nations and supporting organizations, worldwide, maternal deaths have decreased by $44 \%$ during the 25 -year period between 1990 and 2015-from 338 per 1,00,000 live births to an estimated 216. It is estimated that there were $3,03,000$ maternal deaths in the world in 2015. The risk of maternal death also fell considerably

\footnotetext{
* Corresponding author.

E-mail addresses: hiwaleanil@gmail.com (A.J. Hiwale), kailash.das@iipsindia.ac.in, daskc@yahoo.com, kailash.das@iipsindia.ac.in (K. Chandra Das).
} 
from 1 in 73 to 1 in $180 .{ }^{3}$ Maternal deaths account for a significant proportion of all deaths among women of reproductive age, especially in rural areas of India. There are also wide regional disparities: maternal mortality is estimated to be almost twice as high in the four northern states of India, Bihar, Madhya Pradesh, Rajasthan and Uttar Pradesh (823 per 1,00,000 births) than in the rest of India, which is 457 per 1,00, 000 birth. $^{4}$

Geographical influences on women's sexual and reproductive health are significant. "Geographical distribution is usually an important dimension because regions, as well as individuals, can be multiply deprived and because there are usually significant variations in the ill health and in the avoidable or remediable ill health of regions". ${ }^{5}$ UNPF has reported that geographical remoteness is associated with higher probability of dying and disability during pregnancy and childbirth, which has strong association with socioeconomic status, and cultural norms and values of the pregnant women and the communities they live in6.

India has a unique physiography. Due to diversity—geological and geomorphological—classification according to its physical features has challenged the efforts of several scholars. It is now accepted that India can divided into five physiographic divisions: the Himalayan Mountains, the Great Plain of North India, the Peninsular Plateau, the Coastal Plains and the Islands. ${ }^{7}$ There is wide variety in relief features in the vast country in terms of drainage, climate, natural vegetation, wild life, soli, and environment. In recent studies, social scientists have shown a strong association of caste and health status with the utilization of maternal health services across India states and union territories. Emerging evidence suggests stark differences in the health status and utilization of health services between social and geographical areas. The present paper examines the utilization of maternal healthcare services in the different natural regions of India and the differences among them.

\section{Data and Methods}

Data for analysis was taken from the National Family Health Survey4 (2015-16). NFHS-4 was a nationally representative survey of a sample of $6,01,509$ households from the 640 districts of the country. The survey included interviews of 6,99,686 eligible women aged 15-49 years. National Family Health Survey is conducted along the lines of other Demographic Health Surveys. They are multi-round and are conducted with a sample of households that represent more than $99 \%$ of India's population. NFHS collects detailed information related to demographics, health, nutrition of children and women, and related data. All the four rounds of NFHS involved several organizations, such as the Ministry of Health and Family Welfare, International Institute for Population Sciences (IIPS), the United States Agency for International Development (USAID), Department for International Development (DFID), United Nations Children's Fund (UNICEF) and United Nations Population Fund (UNFPA). Out of all women the sample distribution of live birth in the last five years preceding the survey among women age $15-49$ by background characteristics is $1,87,632$.

\subsection{Operational definitions in the study}

Geographical/Natural Region: In the 75th round of the National Sample Survey (NSS) India was divided into 88 natural regions. "Regions were formed in consultation with different Central Ministries, Planning Commission, Registrar General and State Statistical Bureaus, by contiguous grouping districts having similar geographical features, rural population densities and crop-pattern". ${ }^{8}$ NSS's classification system is used in the study.

Maternal Healthcare: According to WHO, "Maternal Health" refers to the health of women during pregnancy, childbirth and the postpartum period. ${ }^{9}$ Maternal Healthcare spans the period beginning with a woman's pregnancy and last still 6 weeks (or 42 days) after delivery.

Full ANC: "Full antenatal care includes at least four antenatal visits, at least one tetanus toxoid (TT) injection, and iron folic acid supplement [taken as] tablets or syrup for 100 or more days". ${ }^{10}$

Partial ANC: A woman is considered as having received partial ANC if she has had two ante natal care services of the four recommended, at least one tetanus toxoid (TT) injection and 100 days of iron folic acid supplement.

Institutional Delivery: "Institutional deliveries are deliveries that take place in a health facility". ${ }^{11}$

Post Natal Care (PNC): Women who got a medical check-up within the first $48 \mathrm{~h}$ (within two days) after delivery are considered to have had a postnatal health check.

\subsection{Geographical grouping}

To identify the regional differences in the use of maternal healthcare services, this study used the 75th round of NSS's classification of India into 88 natural regions. NFHS-4 collected data from 640 districts of the country, which was aggregated natural region-wise using the NSS's system of dividing the country into 88 natural regions based geographical homogeneity or natural characteristics.

\subsection{Data analysis}

Data management and analysis performed using statistical software Stata 13.0. Geographical distribution of the antenatal healthcare services utilization coverage and the differences were determined using geographical mapping techniques. Regional variations in utilization of antenatal care were with the help of ArcGIS 10.5. A composite index was developed to rank the natural regions according to their performance in overall maternal healthcare services: use of full ANC, institutional delivery and PNC.

\subsection{Variables}

Responses to each of the variables Full ANC, Partial ANC, Institutional Delivery and Post Natal Care were obtained in the binary form ('Yes/No), i.e. for the analysis. Full ANC (Yes/No), Partial ANC (Yes/ No), Institutional Delivery (Yes/No), Post Natal Care (Yes/No).

\subsection{Weighted percentage of women receiving antenatal care, institutional delivery and Post Natal Care}

To analyse the patterns and differences in the utilization of services by currently married women across the 88 geographical regions, this study uses weighted proportions of the indicators while calculating regional distribution of Partial ANC, full ANC, use of Institutional Delivery and Post-natal checks.

\subsection{Composite index}

Composite index was used for assessing objectives. The composite considered the three indicators of maternal healthcare: full ANC, institutional delivery and post-natal care. It was constructed using the following formula

$\mathrm{CI}=\frac{\text { Observed value }- \text { Minimum value }}{\text { Maximum value }- \text { Minimum value }}$

\subsection{Geographical mapping}

Geographical mapping methods provide an intuitive means for identifying discrepancies across regions and the country. The differentials in utilization of maternal healthcare services in different geographical regions can be easily identified with the help of geographical maps. Geographical mapping is used in this study for showing the patterns of usage of Partial ANC, full ANC, institutional 
Table 1

Sample distribution, MHCS utilization and Ranking natural regions of India according to their score on the Composite Index women age 15-49 years in the five years preceding the survey (by Natural Regions, in 2015-16).

\begin{tabular}{|c|c|c|c|c|c|c|c|c|c|}
\hline State & Natural Region & Birth & Total & Partial ANC & Full ANC & $\begin{array}{l}\text { Instit. } \\
\text { Deli. }\end{array}$ & PNC & CI & Rank \\
\hline \multirow[t]{4}{*}{ Jammu \& Kashmir } & Jhelum Valley & 2,694 & 6,599 & 78.3 & 20.1 & 94.8 & 83.5 & 65.8009 & 29 \\
\hline & Ladakh & 545 & 1,176 & 72.2 & 26.2 & 90.9 & 84.1 & 66.7609 & 27 \\
\hline & Outer Hills & 2,275 & 5,191 & 63.4 & 24.0 & 72.4 & 59.3 & 51.5942 & 62 \\
\hline & Mountainous & 703 & 2,066 & 46.7 & 50.0 & 91.1 & 84.2 & 74.8209 & 10 \\
\hline \multirow[t]{2}{*}{ Himachal Pradesh } & Trans-Himalayan \& Southern & 1,295 & 4,118 & 58.4 & 36.1 & 75.8 & 73.7 & 61.5242 & 43 \\
\hline & Central & 973 & 3,269 & 60.2 & 37.4 & 80.4 & 78.4 & 65.0842 & 31 \\
\hline \multirow{2}{*}{ Punjab } & Northern & 1,822 & 6,102 & 64.8 & 33.8 & 92.0 & 88.9 & 71.2442 & 15 \\
\hline & Southern & 2,250 & 7,628 & 69.8 & 28.0 & 92.1 & 89.7 & 69.6442 & 20 \\
\hline Chandigarh & Chandigarh & 149 & 505 & 64.5 & 34.1 & 93.5 & 91.4 & 72.6909 & 12 \\
\hline Uttarakhand & Uttarakhand & 4,253 & 11,870 & 83.3 & 11.5 & 72.0 & 58.3 & 46.9775 & 73 \\
\hline \multirow[t]{2}{*}{ Haryana } & Eastern & 3,716 & 10,514 & 73.4 & 20.0 & 79.7 & 67.7 & 55.4609 & 55 \\
\hline & Western & 1,948 & 5,739 & 78.8 & 18.7 & 91.4 & 77.0 & 62.0409 & 40 \\
\hline Delhi & Delhi & 1,240 & 3,938 & 57.6 & 38.9 & 87.0 & 65.8 & 63.5975 & 36 \\
\hline \multirow[t]{5}{*}{ Rajasthan } & Western & 3,041 & 7,415 & 79.3 & 8.1 & 75.6 & 58.6 & 47.1509 & 72 \\
\hline & North-Eastern & 3,808 & 9,871 & 84.0 & 10.1 & 88.7 & 65.3 & 54.3975 & 57 \\
\hline & Northern & 1,774 & 5,323 & 86.3 & 10.3 & 89.4 & 68.8 & 55.8342 & 54 \\
\hline & Southern & 1,316 & 3,233 & 84.5 & 8.9 & 84.2 & 66.0 & 52.7342 & 59 \\
\hline & South-Eastern & 1,904 & 5,388 & 85.5 & 11.5 & 92.3 & 68.3 & 57.0675 & 52 \\
\hline \multirow[t]{5}{*}{ Uttar Pradesh } & Northern Upper Ganga Plains & 5,402 & 12,560 & 83.8 & 9.1 & 69.5 & 74.6 & 50.7509 & 66 \\
\hline & Central & 2,851 & 7,294 & 84.4 & 5.1 & 73.1 & 54.4 & 43.8942 & 78 \\
\hline & Southern Upper Ganga Plains & 7,760 & 17,567 & 84.1 & 4.9 & 65.8 & 61.3 & 43.7042 & 79 \\
\hline & Southern & 1,924 & 5,358 & 90.7 & 3.0 & 82.4 & 57.5 & 47.3275 & 71 \\
\hline & Eastern & 10,480 & 23,710 & 85.0 & 5.8 & 70.5 & 52.6 & 42.6542 & 80 \\
\hline \multirow[t]{2}{*}{ Bihar } & Northern & 9,108 & 18,508 & 87.3 & 2.9 & 61.6 & 40.2 & 34.6009 & 85 \\
\hline & Central & 7,545 & 16,865 & 91.9 & 4.2 & 75.6 & 57.3 & 45.3542 & 74 \\
\hline Sikkim & Sikkim & 884 & 3,343 & 60.4 & 39.3 & 95.2 & 74.9 & 69.5009 & 21 \\
\hline Arunachal Pradesh & Arunachal Pradesh & 3,781 & 10,226 & 66.9 & 3.6 & 55.4 & 30.2 & 29.4175 & 87 \\
\hline Nagaland & Nagaland & 3,020 & 6,646 & 69.7 & 2.4 & 35.7 & 23.3 & 20.1275 & 88 \\
\hline \multirow[t]{2}{*}{ Manipur } & Plains & 2,672 & 5,788 & 54.1 & 43.5 & 84.5 & 75.6 & 67.5609 & 25 \\
\hline & Hills & 1,652 & 3,084 & 75.4 & 12.7 & 46.5 & 44.5 & 34.2375 & 86 \\
\hline Mizoram & Mizoram & 3,213 & 7,006 & 54.9 & 38.2 & 80.1 & 64.1 & 60.5109 & 48 \\
\hline Tripura & Tripura & 1,144 & 3,646 & 87.9 & 7.8 & 82.8 & 63.1 & 50.9175 & 65 \\
\hline Meghalaya & Meghalaya & 2,890 & 5,559 & 63.9 & 23.4 & 54.5 & 54.9 & 43.9709 & 77 \\
\hline Assam & Central Brahmaputra Plains & 1,620 & 3,877 & 79.5 & 17.3 & 75.3 & 52.3 & 47.9909 & 70 \\
\hline & Plains Eastern & 2,003 & 5,466 & 64.9 & 32.1 & 87.3 & 74.2 & 64.2475 & 33 \\
\hline & Cachar Plain & 1,606 & 3,569 & 82.7 & 10.2 & 59.6 & 56.8 & 41.9042 & 82 \\
\hline & Plains Western & 3,184 & 7,731 & 70.2 & 13.6 & 69.2 & 51.6 & 44.4909 & 76 \\
\hline West Bengal & Himalayan & 594 & 2,017 & 76.2 & 21.7 & 87.8 & 74.2 & 60.9109 & 46 \\
\hline & Eastern Plains & 1,551 & 4,485 & 80.0 & 17.8 & 71.7 & 55.7 & 48.0909 & 68 \\
\hline & Southern Plains & 641 & 1,977 & 80.4 & 18.9 & 73.9 & 61.4 & 51.0475 & 63 \\
\hline & Central Plains & 627 & 2,138 & 69.8 & 28.4 & 87.0 & 70.3 & 61.6175 & 41 \\
\hline & Western Plains & 990 & 3,129 & 72.9 & 25.8 & 78.6 & 67.8 & 57.0809 & 51 \\
\hline Jharkhand & Hazaribagh Plateau & 5,176 & 12,834 & 88.0 & 8.3 & 64.0 & 53.2 & 41.5142 & 83 \\
\hline & Ranchi Plateau & 3,627 & 8,615 & 84.9 & 7.8 & 64.3 & 42.0 & 37.7209 & 84 \\
\hline Odish & Northern & 2,815 & 7,884 & 70.7 & 27.2 & 88.1 & 80.5 & 64.9609 & 32 \\
\hline & Coastal & 2,502 & 7,197 & 76.7 & 19.6 & 92.8 & 78.7 & 63.4142 & 37 \\
\hline & Southern & 3,544 & 8,857 & 73.2 & 23.5 & 79.4 & 77.0 & 59.6242 & 50 \\
\hline Chhattisgarh & Northern Chhattisgarh & 860 & 2,167 & 77.8 & 14.5 & 67.1 & 54.9 & 45.1975 & 75 \\
\hline & Mahanadi Basin & 4,104 & 11,012 & 75.2 & 23.0 & 74.0 & 72.1 & 56.0575 & 53 \\
\hline & Southern Chhattisgarh & 1,719 & 3,996 & 78.1 & 19.9 & 71.1 & 63.0 & 51.0109 & 64 \\
\hline Madhya Pradesh & Northern & 2,852 & 7,812 & 88.2 & 8.5 & 88.2 & 60.6 & 52.1175 & 61 \\
\hline & Vindhya & 2,966 & 7,779 & 83.1 & 5.8 & 74.4 & 47.9 & 42.3909 & 81 \\
\hline & Central & 1,779 & 4,628 & 82.7 & 10.5 & 82.4 & 52.1 & 48.0209 & 69 \\
\hline & Malwa & 4,372 & 11,742 & 80.4 & 13.0 & 88.0 & 63.1 & 54.3742 & 58 \\
\hline & South Western & 2,918 & 7,890 & 79.7 & 13.0 & 76.5 & 59.1 & 49.2042 & 67 \\
\hline & South & 2,294 & 6,978 & 79.1 & 18.5 & 81.8 & 57.2 & 52.2042 & 60 \\
\hline Gujarat & Kachchh & 233 & 606 & 67.8 & 29.6 & 85.1 & 70.6 & 61.4309 & 44 \\
\hline & Dry Areas & 516 & 1,378 & 76.7 & 17.1 & 91.8 & 58.1 & 55.3575 & 56 \\
\hline & Plains Northern & 1,293 & 3,936 & 58.2 & 38.1 & 93.7 & 68.9 & 66.5875 & 28 \\
\hline & Saurashtra & 1,452 & 4,615 & 69.3 & 28.1 & 91.7 & 60.2 & 59.7075 & 49 \\
\hline & South Eastern & 2,236 & 6,490 & 63.0 & 30.1 & 86.2 & 69.4 & 61.5775 & 42 \\
\hline Daman \& Diu & Daman \& Diu & 328 & 922 & 56.2 & 29.7 & 91.5 & 61.5 & 60.5842 & 47 \\
\hline Dadra \& Nagar Haveli & Dadra \& Nagar Haveli & 239 & 594 & 62.9 & 32.9 & 89.2 & 66.7 & 62.6309 & 39 \\
\hline Maharashtra & Inland Northern & 888 & 2,637 & 70.3 & 25.8 & 82.5 & 76.2 & 61.2042 & 45 \\
\hline & Inland Eastern & 1,441 & 4,622 & 64.3 & 33.5 & 91.4 & 79.2 & 67.7375 & 24 \\
\hline & Eastern & 695 & 2,386 & 51.6 & 45.9 & 92.8 & 78.4 & 72.0775 & 13 \\
\hline & Inland Central & 1,964 & 5,508 & 71.8 & 25.2 & 90.1 & 78.1 & 64.1375 & 34 \\
\hline & Coastal & 901 & 2,917 & 60.0 & 36.0 & 95.1 & 83.0 & 71.0642 & 16 \\
\hline & Inland Western & 1,116 & 3,724 & 62.5 & 34.7 & 94.7 & 80.8 & 69.7442 & 19 \\
\hline Telangana & Inland North Weste & 1,114 & 3,411 & 54.3 & 43.0 & 90.9 & 78.9 & 70.6075 & 18 \\
\hline & Inland North Easte & 636 & 2,192 & 59.1 & 40.9 & 96.4 & 91.1 & 75.8209 & 7 \\
\hline Andhra Pradesh & Coastal Northern & 786 & 3,032 & 57.6 & 41.4 & 93.3 & 82.1 & 71.9942 & 14 \\
\hline
\end{tabular}


Table 1 (continued)

\begin{tabular}{|c|c|c|c|c|c|c|c|c|c|}
\hline State & Natural Region & Birth & Total & Partial ANC & Full ANC & $\begin{array}{l}\text { Instit. } \\
\text { Deli. }\end{array}$ & PNC & CI & Rank \\
\hline \multirow{6}{*}{ Karnataka } & Coastal Southern & 659 & 2,510 & 53.1 & 46.1 & 96.5 & 83.3 & 74.9609 & 8 \\
\hline & Inland Southern & 785 & 2,495 & 54.4 & 44.5 & 88.2 & 76.0 & 69.2675 & 22 \\
\hline & Inland Northern & 3,074 & 9,402 & 60.5 & 35.9 & 92.6 & 61.7 & 63.1175 & 38 \\
\hline & Coastal and Ghats & 521 & 1,728 & 62.5 & 33.6 & 97.0 & 74.1 & 67.9509 & 23 \\
\hline & Inland Eastern & 649 & 2,349 & 66.9 & 27.4 & 97.8 & 66.8 & 63.6875 & 35 \\
\hline & Inland Southern & 1,547 & 5,524 & 65.0 & 30.8 & 96.9 & 69.8 & 65.5175 & 30 \\
\hline Goa & Goa & 344 & 1,095 & 36.2 & 63.1 & 98.3 & 92.5 & 84.3175 & 3 \\
\hline Lakshadweep & Lakshadweep & 260 & 738 & 34.4 & 65.6 & 99.2 & 92.6 & 85.4909 & 1 \\
\hline \multirow[t]{2}{*}{ Kerala } & Northern & 1,085 & 3,835 & 33.8 & 66.0 & 100.0 & 90.4 & 85.1709 & 2 \\
\hline & Southern & 1,023 & 4,259 & 43.4 & 56.4 & 99.9 & 87.3 & 80.9009 & 4 \\
\hline \multirow[t]{4}{*}{ Tamil Nadu } & Coastal Northern & 1,351 & 4,811 & 49.9 & 47.5 & 99.6 & 74.1 & 73.4275 & 11 \\
\hline & Inland & 1,638 & 5,779 & 44.5 & 52.4 & 98.9 & 79.7 & 76.6942 & 6 \\
\hline & Southern & 1,564 & 5,357 & 59.9 & 34.3 & 98.9 & 70.4 & 67.5575 & 26 \\
\hline & Coastal & 1,528 & 5,113 & 52.6 & 42.9 & 99.2 & 71.9 & 70.9942 & 17 \\
\hline Puducherry & Puducherry & 872 & 2,850 & 43.1 & 55.6 & 99.9 & 84.9 & 79.8042 & 5 \\
\hline Andaman and Nicobar Island & Andaman and Nicobar Island & 518 & 1,927 & 46.2 & 53.5 & 96.3 & 75.8 & 74.8909 & 9 \\
\hline Total & & $1,87,632$ & $4,99,627$ & 73.7 & 21.0 & 81.2 & 65.2 & - & - \\
\hline
\end{tabular}

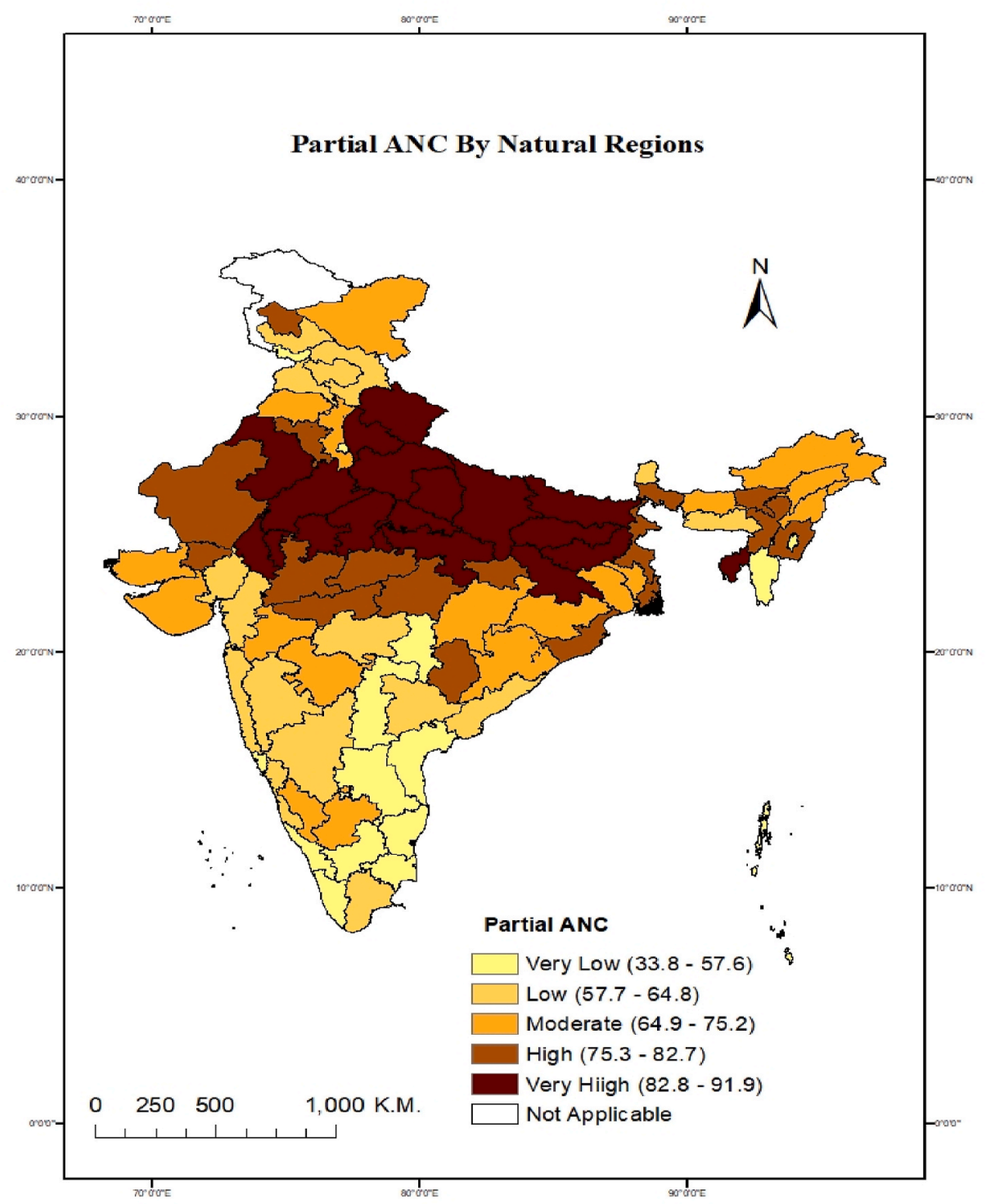

Fig. 1. Coverage of partial ANC in the natural regions of India. 


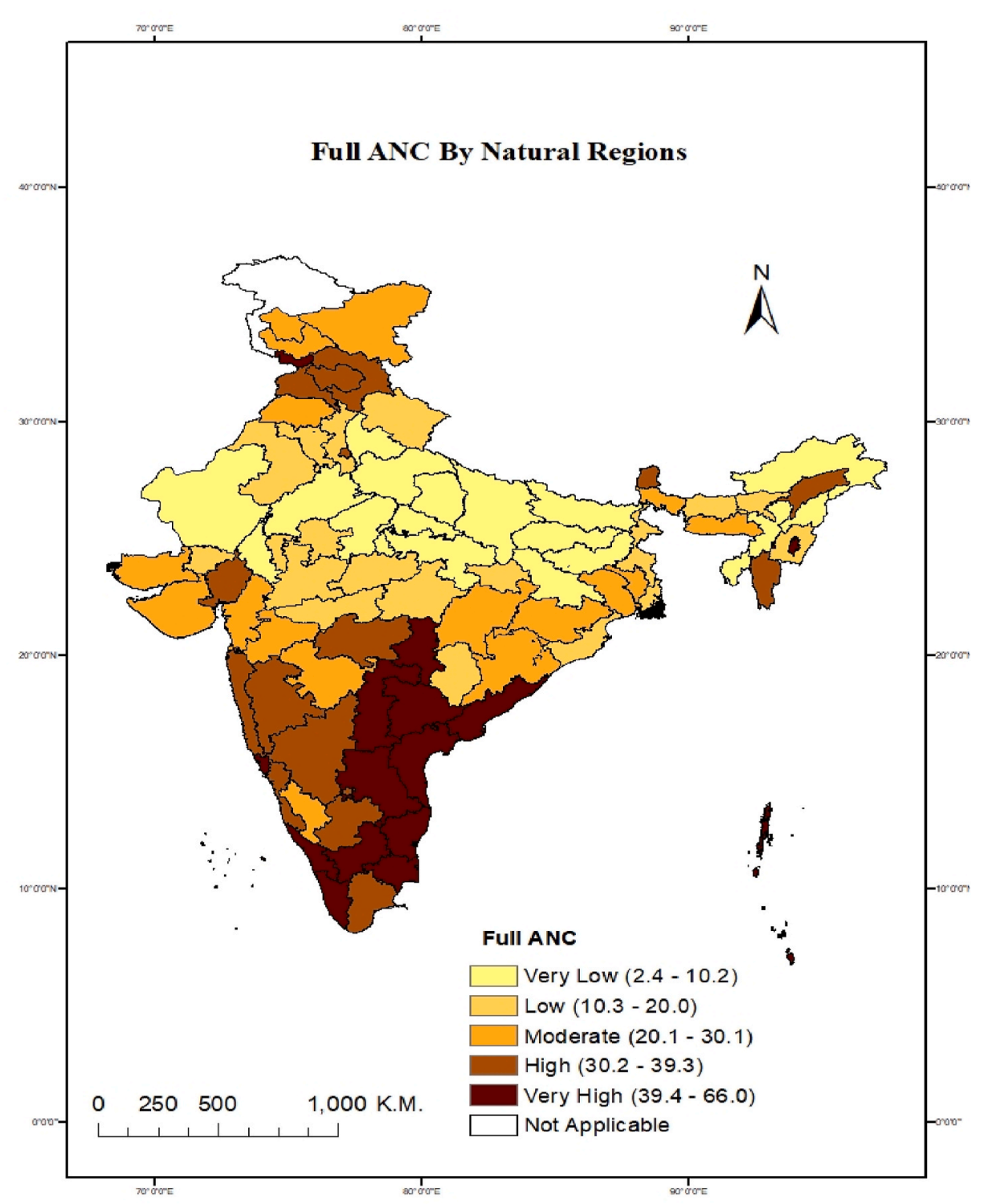

Fig. 2. Coverage of full ANC in the natural regions of India.

delivery, and Post-natal care at a national or macro-level, as well as the differences in utilization. The geographical maps were prepared with the help of ArcGIS software.

\section{Results}

Table 1 shows the distribution of live birth over the natural regions in the last five years preceding the survey. The $1,87,632$ women in the sample represented all 88 natural regions of India. Women from eastern Uttar Pradesh formed the largest group from a natural region $(10,480)$, while those from Chandigarh were the smallest (149). The second largest group in the sample was from Northern Bihar $(9,108)$ followed by the Southern Upper Ganga Plains of Uttar Pradesh (7,760), Central Bihar $(7,545)$, Northern Upper Ganga Plains of Uttar Pradesh $(5,402)$, Hazaribagh Plateau of Jharkhand $(5,176)$, Malwa region of Madhya Pradesh $(4,372)$, Uttarakhand $(4,253)$, Mahanadi Basin of Chhattisgarh $(4,104)$ and North-Eastern Rajasthan $(3,808)$.

Other small-sized groups besides Chandigarh were from Kachchh region of Gujrat (233), Dadra \& Nagar Haveli (239), Lakshadweep (260), Daman \& Diu (328), Goa (344), Dry Areas of Gujrat (516), Andaman and Nicobar Island (518), Costal and Ghats of Karnataka
(521), and the Ladakh region of Jammu \& Kashmir (545).

\subsection{Differences in coverage of ANC among natural regions}

Table 1 presents data on coverage of partial and full ANC among women age 15-49. The utilization of partial ANC ranges from $33.8 \%$ to 91.9\%. Utilization is lowest in the Northern Kerala region (33.8\%) and, in ascending order, higher in Lakshadweep (34.4\%), Goa (36.2\%), Puducherry (43.1\%), Southern Kerala (43.4\%), Inland Tamil Nadu (44.5\%), and Andaman and Nicobar Island (46.2\%), the mountainous region of Jammu and Kashmir (46.7\%), Coastal northern Tamil Nadu (49.9\%) and Eastern Maharashtra (51.6\%). However, these ten natural regions were seen to perform better in full ANC in the country.

Central Bihar showed highest utilization of partial ANC (91.9\%) and followed by Southern Uttar Pradesh (90.7\%), Northern Madhya Pradesh (88.2\%), Hazaribagh Plateau of Jharkhand (88.0\%), Tripura (87.9\%), Northern Bihar (87.3\%), Northern Rajasthan (86.3\%), South-Eastern Rajasthan (85.5\%), Eastern Uttar Pradesh (85.0\%) and Ranchi Plateau of Jharkhand (84.9\%). It is also seen from the table that in the regions with high percentage of use of partial ANC services, the proportion of women not using full ANC was also high (Fig. 1). 


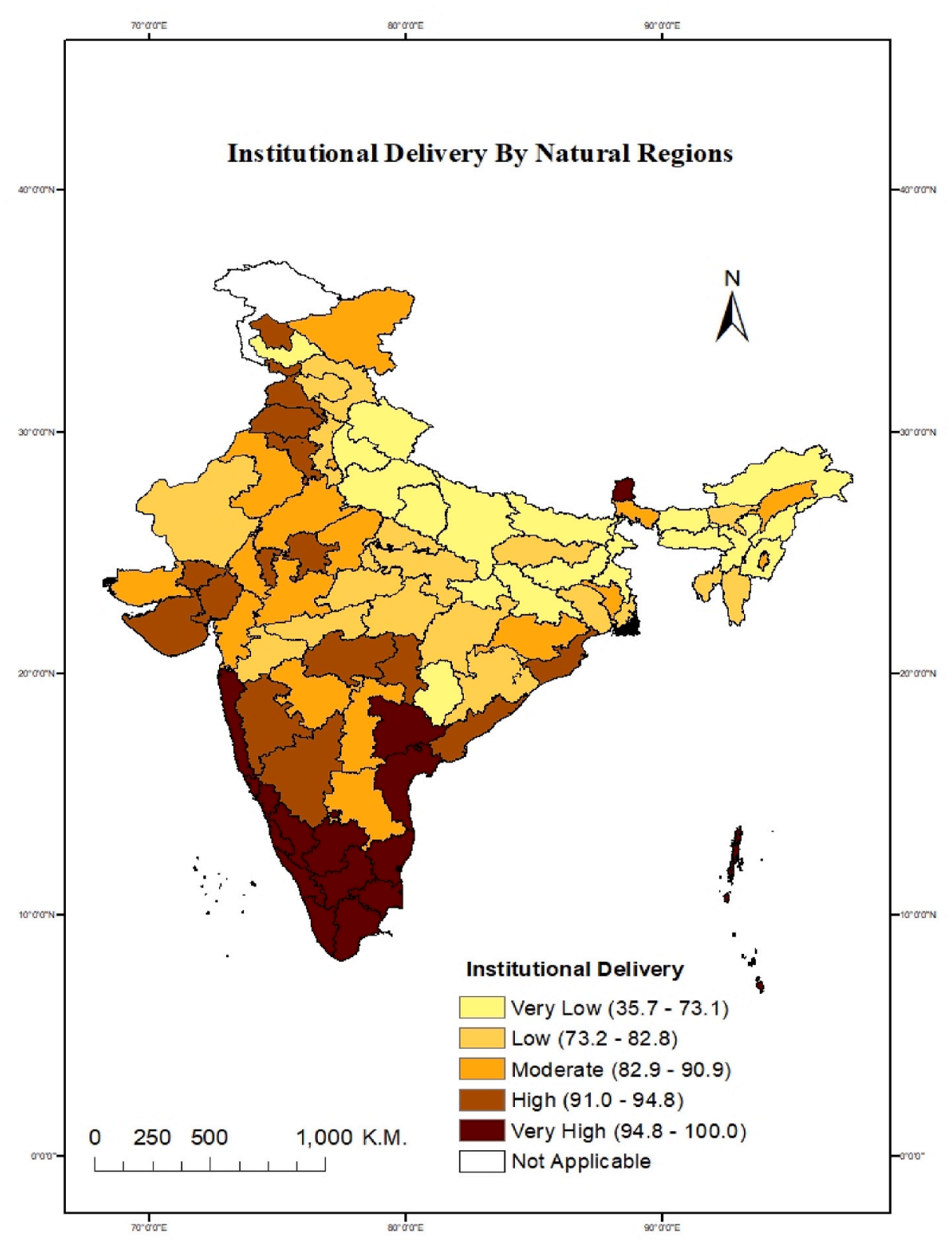

Fig. 3. Institutional deliveries in the natural regions of India (2015-16).

\subsection{Utilization of full ANC}

The utilization of full ANC among women varied widely from $2.4 \%$ in Nagaland to $66.0 \%$ in Northern Kerala. Other states where utilization of full ANC was low included Northern Bihar (2.9\%), Southern Uttar Pradesh (3.0\%), Arunachal Pradesh (3.6\%), and Central Bihar (4.2\%). Nearly five women in a hundred in Southern Upper Ganga plains (4.9\%) and the Central (5.1\%) region of Uttar Pradesh utilized full ANC care services. Other regions included the Vindhya region of Madhya Pradesh (5.8\%), Eastern part of Uttar Pradesh (5.8\%), Tripura (7.8\%), and the Ranchi Plateau of Jharkhand (7.8\%). In Western Rajasthan utilization of full ANC was $8.1 \%$, and higher in Hazaribagh Plateau of Jharkhand (8.3\%), and Northern Madhya Pradesh (8.5\%), Southern Rajasthan (8.9\%) and Northern Upper Ganga Plains of Uttar Pradesh (9.1\%). In North-Eastern Rajasthan, utilization of full ANC was $10.1 \%, 10.2 \%$ in the Cachar Plain of Assam, 10.3\% in Northern Rajasthan, 10.5\% in Central Madhya Pradesh, $11.5 \%$ each in South-Eastern and Uttarakhand, $12.7 \%$ in Manipur Hills, $13 \%$ each in the Malwa region and South Western Madhya Pradesh, $13.6 \%$ in the Plains of Western Assam
(13.6\%) and $14.5 \%$ in Northern Chhattisgarh.

As can be seen from the table, the highest utilization of full ANC was in Lakshadweep (65.6\%) and followed by Goa (63.1\%), Southern Kerala (56.4\%), Puducherry (55.6\%), Andaman and Nicobar Island (53.5\%), the Inland area of Tamil Nadu (52.4\%), the Mountainous region of Jammu and Kashmir (50\%), Coastal Northern region of Tamil Nadu (47.5\%), Coastal Southern region of Andhra Pradesh (46.1\%) and Eastern Maharashtra (45.9\%).

In Inland Southern Andhra Pradesh utilization of full ANC services was $44.5 \%$ and followed by, in descending order, Manipur Plains (43.5\%), Inland North Western Telangana (43\%), Coastal Tamil Nadu (42.9\%), Coastal Northern Andhra Pradesh (41.4\%) and Inland North Eastern Telangana (40.9\%) (Fig. 2).

Data in the table show that all regions in south India are performing better in the utilization of full ANC than the regions in north India. The only region in north India that was ranked in the ten best performing regions was the Mountainous region of Jammu and Kashmir.

Women in sixteen of the country's eighty-eight natural regions were not using full ANC. Nineteen regions had less than two women who used 


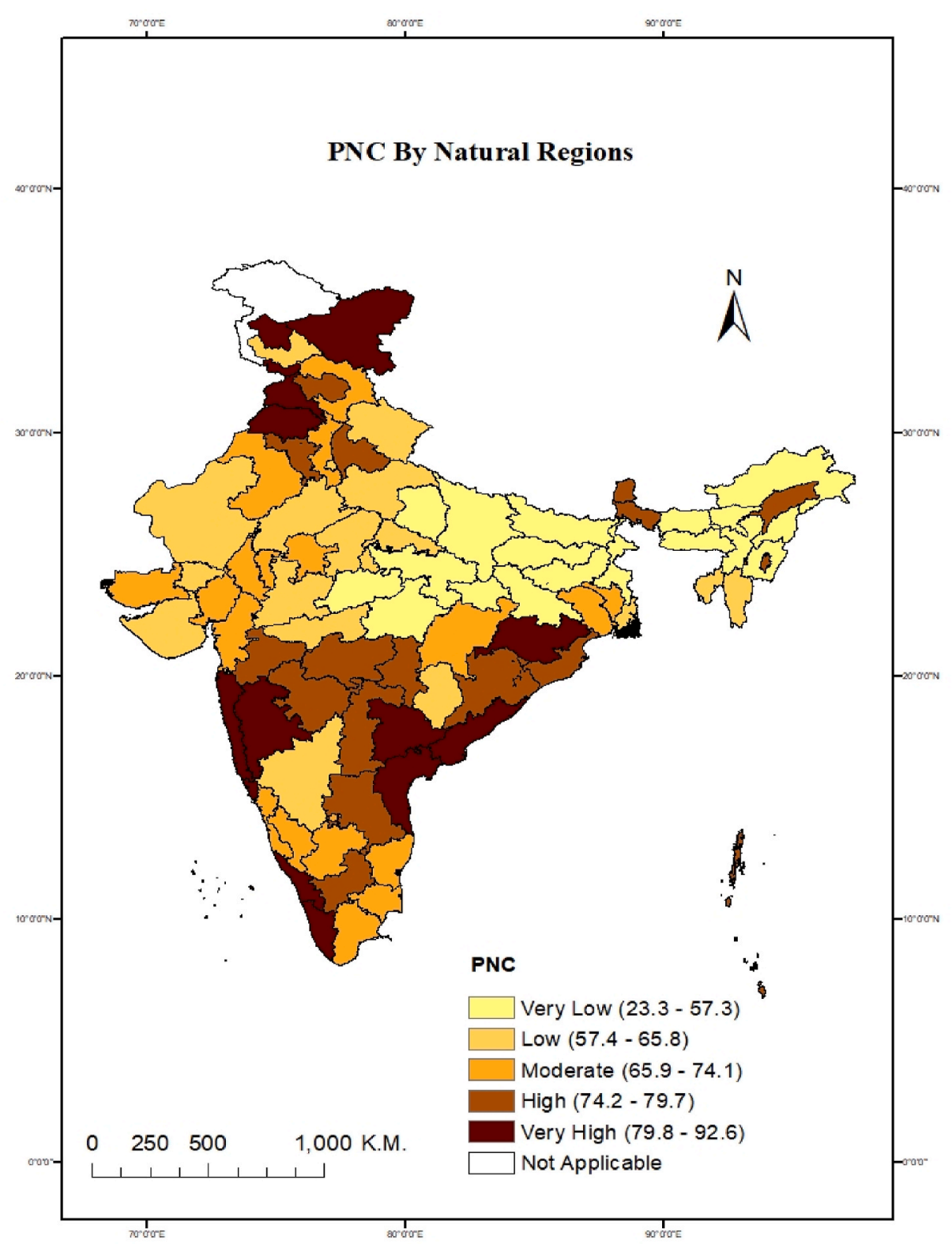

Fig. 4. PNC cover in India's Natural Regions of India (2015-16).

full ANC; and in eighteen regions, the number of women using full ANC was less than three. In seventeen natural regions, more than $40 \%$ of the women had full ANC and in seven regions, more than half received full ANC services.

\subsection{Regional differences in place of delivery}

As seen in Table 1 , the percentages of women aged 15-49 years having live births in institutions in 2015-16 varied from $35.7 \%$ to $100 \%$. The effect of geographical isolation is seen in the choice of place of delivery. Institutional delivery was the highest in Northern Kerala (100\%) and lowest in the Nagaland (35.7\%). Near-universal institutional delivery was also found in Southern Kerala (99.9\%), Puducherry (99.9\%), Coastal Northern Tamil Nadu (99.6\%) and Lakshadweep (99.2\%). Other regions with very high percentage of institutional delivery were Southern Tamil Nadu (98.9\%), Inland Tamil Nadu (98.9\%), Goa (98.3\%), Inland Eastern Coastal (97.8\%) and Ghats (97\%), and the Inland Southern region Karnataka (96.9\%), Coastal Southern Andhra Pradesh (96.5\%), Inland North East Telangana (96.4\%) and Andaman and Nicobar Island (96.3\%).

Besides Nagaland, other regions with low percentages of institutional deliveries include Manipur Hills (46.5\%), Meghalaya (54.5\%) and Arunachal Pradesh (55.4\%). It was relatively higher in the Cachar Plain of Assam (59.6\%), Northern Bihar (61.6\%), Hazaribagh Plateau (64\%) and Ranchi Plateau (64.3\%) of Jharkhand. In Southern Upper Ganga Plains of Uttar Pradesh, the proportion of institutional deliveries was $65.8 \%, 67.1 \%$ in Northern Chhattisgarh, $69.2 \%$ in Plains Western of Assam $69.2 \%$ and $69.5 \%$ in the Northern Upper Ganga Plains of Uttar Pradesh. Relatively higher utilization of institutional deliveries were seen in Eastern Uttar Pradesh (70.5\%), Southern Chhattisgarh (71.1\%), Eastern Plains of West Bengal (71.7\%), Uttarakhand (72\%), Outer Hills of Jammu \& Kashmir (72.4\%), Central Uttar Pradesh (73.1\%), Southern Plains of West Bengal (73.9\%), Mahanadi Basin of Chhattisgarh (74\%), Vindhya region of Madhya Pradesh (74.4\%) and Central Brahmaputra Plains of Assam (75.3\%) (Fig. 3). 


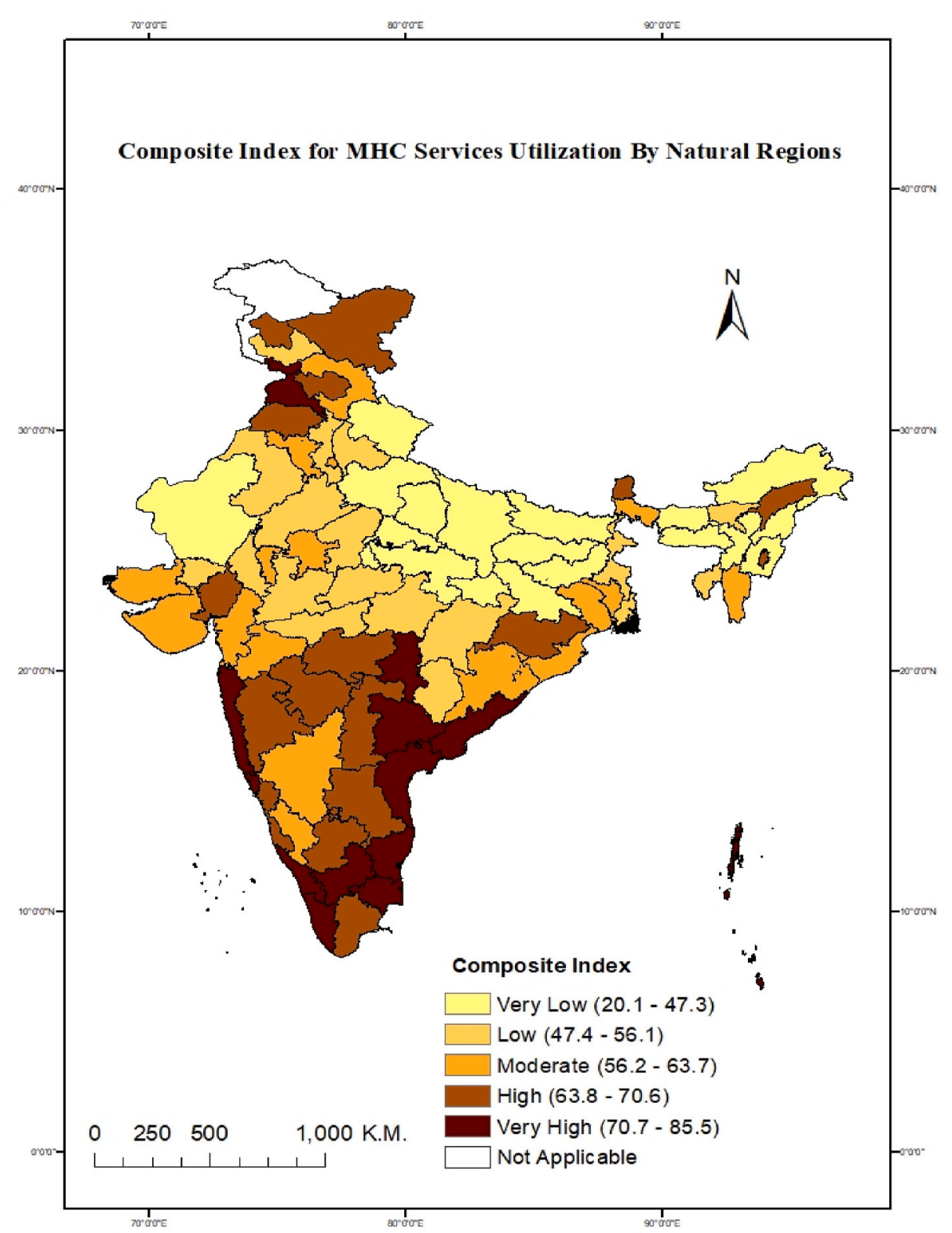

Fig. 5. Composite Index of utilization of maternal healthcare services by natural regions (2015-16).

\subsection{Differences in utilization of PNC among natural regions}

Table 1 presents data on coverage of post-natal care among women aged 15-49 years who had live births in the five years preceding the survey in 2015-16. Nagaland showed the lowest utilization of PNC (23.3\%), while Lakshadweep had the highest (92.6\%). Utilization of PNC services was $92.5 \%$ in Goa, $91.4 \%$ in Chandigarh, $91.1 \%$ in Inland North Eastern Telangana, $90.4 \%$ in Northern Kerala, $89.7 \%$ and $88.9 \%$ respectively in Southern and Northern (88.9\%) Punjab, and 87.3\% in Southern Kerala. Other states with high utilization of PNC services were Puducherry (84.9\%), Mountainous region (84.2\%), Ladakh region (84.1\%), Jhelum Valley region of Jammu \& Kashmir (83.5\%), Coastal Southern Andhra Pradesh (83.3\%), Coastal Maharashtra (83\%), Coastal Northern Andhra Pradesh (82.1\%), Inland Western Maharashtra (80.8\%), and Northern Odisha (80.5\%).

Besides Nagaland, regions showing low utilization of PNC services were Arunachal Pradesh (30.2\%), Northern Bihar (40.2\%), Ranchi Plateau of Jharkhand (42\%) and Manipur Hills (44.5\%) were getting PNC. Relative to these states, a higher proportion of utilization of PNC was seen in the Vindhya region of Madhya Pradesh (47.9\%), Western Plains of Assam (51.6\%), Central Madhya Pradesh (52.1\%), Central Brahmaputra Plains of Assam (52.3\%), Eastern Uttar Pradesh (52.6\%), Hazaribagh Plateau of Jharkhand (53.2\%), Central Uttar Pradesh (54.4\%), Northern Chhattisgarh (54.9\%), and Meghalaya (54.9\%) (Fig. 4).

\subsection{Ranking natural regions for utilization of maternal healthcare} services in 2015-16 using a composite index

Ranking of the regions for utilization of maternal health care is presented in Table 1. A composite index of utilization in 2015-16 was developed with which the regions were ranked. Three variables were considered for computing the index: full ANC, institutional delivery and post-natal care services. Table 1 shows the ranking of the regions based on the overall performance of each region in all the three indicators. Lakshadweep (CI 85.49,087) was ranked first followed by, in that order, Northern Kerala, Goa, Southern Kerala, Puducherry, Inland Tamil Nadu, Inland North East Telangana, Coastal Southern Andhra Pradesh, 
Andaman and Nicobar Island, and Mountainous region of Jammu \& Kashmir (CI 74.82,087).

Nagaland ranked the lowest in utilization of maternal healthcare services (CI 20.12,753). Above Nagaland, in ascending order, were Arunachal Pradesh, Manipur Hills, Northern Bihar, Ranchi and Hazaribagh Plateaus of Jharkhand, Cachar Plain of Assam, Vindhya region of Madhya Pradesh, Eastern region, Southern Upper Ganga Plains and Central part of Uttar Pradesh, Meghalaya, Plains Western of Assam, Northern Chhattisgarh, and Central Bihar (CI 45.35,420) (Fig. 5). The low CI values indicate poor utilization of maternal healthcare services in the respective regions.

\section{Discussion}

Data showing the differences in utilization of maternal healthcare were presented in this paper. This paper aimed at providing the differentials of maternal health care utilization which includes full antenatal care, institutional deliveries and postnatal care services by natural regions. Results clearly show that there is wide gap in the utilization of maternal health care services by the natural regions. Full ANC is considered as one of the important interventions to increase the chances of successful deliveries and positive health outcomes for both mother and infant. However, the results show that the full ANC services are uniformly utilized across the natural regions results were found in previous studies in India.

The results show wide differences in the utilization of maternal health services among the natural regions of India. The natural regions in Southern India led the rest of the country in the utilization of all components of maternal healthcare. Regions in north and north-east India ranked low in the utilization of maternal health services. One possible reason for the wide differences in the utilization of maternal healthcare services is that these services are not widely available in the regions that perform poorly. Some previous studies had reported the similar results. ${ }^{12}$

A lower proportion of Women from natural regions located in the Himalayan mountain ranges, including Nagaland, Arunachal Pradesh, Manipur Hills, Meghalaya, and the Vindhya mountainous ranges are seen to utilize maternal healthcare services as compared to other regions. These regions also characterized by dense forest cover- $52 \%$ of land area in Nagaland, 61\% in Arunachal Pradesh, 78\% in Manipur Hills, and $42 \%$ in Meghalaya. ${ }^{13}$ Utilization of Maternal Healthcare services was also low Northern Chhattisgarh which also has dense forest cover. Northern Chhattisgarh includes two districts, Koriya and Surguja. Koriya has $62.03 \%$ forest cover and Surguja $45.02 \%{ }^{14}$

Utilization of MHCS was also low in the plains of Ganga and Brahmaputra of the country. They include Northern and Central Bihar, the Eastern region, Southern Upper Ganga Plains and Central part of Uttar Pradesh, Cachar and the Western Plains of Assam. The plateau regions of central India-the Ranchi Plateau and Hazaribagh Plateau of Jharkhand - also showed poor utilization of maternal healthcare services. The influence of geographical factors was invisible in the natural regions of south Indian regions where utilization of maternal healthcare services were high in Lakshadweep, Northern Kerala, Goa, Southern Kerala, Puducherry, Inland Tamil Nadu, Inland North East Telangana, Coastal Southern Andhra Pradesh, and Andaman and Nicobar Island.

\section{Conclusion}

Differences in the utilization of MCHS by women can be seen among
India's natural regions. Utilization is lagging in the Himalayan Mountain ranges, areas with dense forest cover, the Ganga and Brahmaputra plains, and the Desert region of Rajasthan. This study establishes that geographical remoteness significantly impacts delivery of MHCS. Such regions had low utilization of institutional delivery services. The influence of geographical factors was invisible in the natural regions of south Indian regions.

\section{Funding statement}

This research did not receive any specific grant from funding agencies in the public, commercial, or not-for-profit sectors.

\section{Data availability statement}

The data used for the study is obtained from the web portal of The DHS Program (https://www.dhsprogram.com/data/available-datasets. $\mathrm{cfm})$. No separate ethics statement and consent for publication was required for this study as the NFHS-IV collect the secondary data from the health facilities of India.

\section{Declaration of competing interest}

None to declare.

\section{Acknowledgment}

None to declare.

\section{References}

1 Chandramouli DC. Child and Maternal Mortality; 1990-2015. 2011.

2 General Assembly. Transforming Our World: The 2030 Agenda for Sustainable Development. 16301. General Assembley 70 session; 2015.

3 WHO, UNICEF, UNFPA WBG and UNPD. Trends in Maternal Mortality : 1990 to 2015 [Internet]. World Health Organization; 2015. Available from: http://whqlibdoc. who. int/publications/2010/9789241500265_eng.pdf.

4 Mari Bhat PN, Navaneetham K, Rajan SI. Maternal Mortality in India; Estimates from an Econometric Model. Dharward; 1992.

5 Culyer AJ. Equity - some theory and its policy implications. J Med Ethics [cited 2017 Aug 22];27(4):275-83. Available from: https://www.ncbi.nlm.nih.gov/pmc/artic les/PMC1733434/pdf/v027p00275.pdf; 2001 [Internet].

6 United Nations Population Fund. Rich mother, poor mother; the social determinants of maternal dealth and disability [cited 2017 Jun 14]. Available from: http://www. unfpa.org/sites/default/files/resource-pdf/EN-SRH fact sheet-Poormother.pdf; 2012 [Internet]

7 Khullar DR. India - A Comprehensive Geography. 2005.

8 Sastry NS. concepts and definitions used in NSS [internet]. Golden jubilee publication http://mospi.nic.in/sites/default/files/publication_reports/concepts_go lden.pdf; 2001 [cited 2018 Apr 6]. Available from:.

9 World Health Organization. Maternal health [internet]. World Health Organization. World Health Organization http://www.who.int/topics/maternal_health/en/; 2016 [cited 2017 Jun 21]. Available from:.

10 IIPS. National Family Health Survey India; India Fact Sheet. 2016.

11 International Institute for Population Sciences (IIPS). National Family Health Survey (NFHS-4) 2015-16. Mumbai: IIPS; 2017.

12 Awasthi A, Pandey CM, Chauhan RK, Singh U. Disparity in maternal, newborn and child health services in high focus states in India: a district-level cross-sectional analysis [cited 2017 Sep 13];6(8):e009885. Available from: http://bmjopen.bmj. com/content/bmjopen/6/8/e009885.full.pdf; 2016. BMJ Open [Internet].

13 Forest Survey of India. India state of forest report 2019 [internet]. Forest Survey of India Ministry of Environment, Forest \& Climate Change Government of India http://www.fsi.org.in/cover_2011/uttarakhand.pdf\%5C; 2019. Vol. I.

14 Forest Survey of India. India state of forest report 2019 [internet]. Forest Survey of India Ministry of Environment, Forest \& Climate Change Government of India http://www.fsi.org.in/cover_2011/uttarakhand.pdf\%5C; 2019. Vol. II. 